\section{Liver Tear: A Previously Unreported Serious Complication of Endoscopic Balloon Dilation for Benign Gastric Outlet Obstruction}

Endoscopic balloon dilation is a useful alternative to surgery for the treatment of gastric outlet obstruction, particularly in patients who are unfit for surgery or do not wish to undergo operation. Perforation is a known complication of endoscopic balloon dilation [1-4], but associated tearing of the liver has not been previously reported. We present a case of duodenal perforation and liver tear secondary to balloon dilation for acute gastric outlet obstruction.

A 53-year-old lady presented with symptoms of gastric outlet obstruction and weight loss of $12 \mathrm{~kg}$. An upper gastrointestinal endoscopy revealed pyloric stenosis (Figure $\mathbf{1}$ ). Biopsies of the pyloric channel showed acute inflammation. As the patient was very reluctant to undergo surgery, conservative treatment in the form of fasting, nasogastric suction, and administration of omeprazole was commenced.

However pyloric stenosis was still present after 1 week of conservative treatment, and therefore through-the-scope dilation was performed using a Microvasive balloon (Boston Scientific, Natick, Massachusetts, USA). The balloon was gradually inflated to $18 \mathrm{~mm}$. During the procedure the duodenum was perforated, and the liver

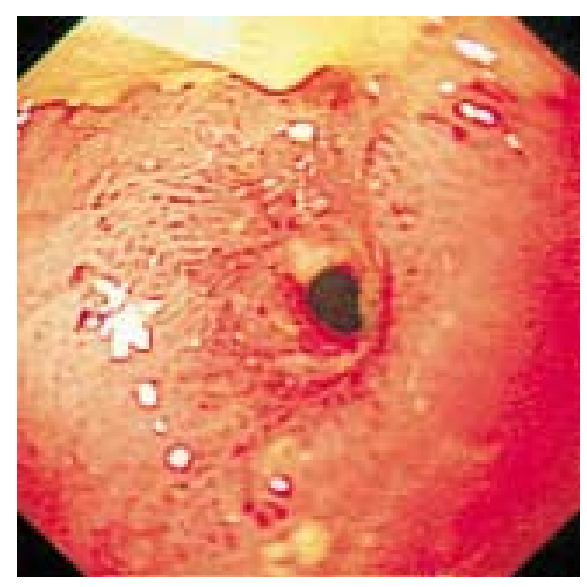

Figure 1 The pyloric stenosis. capsule was seen through the perforation (Figure 2). After the procedure, the patient's haemoglobin level fell from a preoperative level of $11 \mathrm{~g} / \mathrm{dl}$ to $6 \mathrm{~g} / \mathrm{dl}$ (normal range $11.5-16.5 \mathrm{~g} / \mathrm{dl}$ ) and she became haemodynamically unstable. Emergency laparotomy was carried out. Blood was noted in the peritoneal cavity, and also a $1-\mathrm{cm}$ longitudinal perforation of the anterosuperior wall of the duodenum and a liver tear measuring $2.5 \times 1.5 \times 0.5 \mathrm{~cm}$, on the undersurface of the right lobe of the liver close to the duodenal perforation. No active bleeding was noted at operation, but the liver tear was possibly the main source of bleeding. The duodenal perforation was closed and truncal vagotomy and gastrojejunostomy were carried out. The liver tear was repaired using chromic catgut. The patient made an uneventful postoperative recovery.

The possibility of serious complications, such as this one which required surgery, should be borne in mind when balloon dilation is offered as an alternative treatment to surgery. The optimal size for dilation is $15 \mathrm{~mm}$ [1], and dilation to $18 \mathrm{~mm}$ may have caused perforation in our patient. The liver tear might possibly have been caused by direct injury from the guide wire or the balloon.

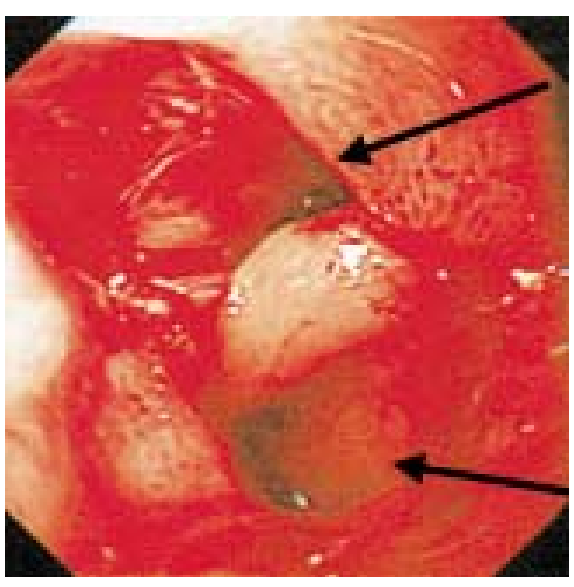

Figure 2 The liver capsule could be seen through the perforation (upper arrow: perforation, arrow down: lumen).

\section{Acknowledgement}

This case report was presented at the Spring Meeting of the Ulster Society of Gastroenterology, Belfast, UK, on 8 March 2001.

\section{R. S. Date, R. Makar, N. Das,}

\section{K. J. S. Panesar}

Department of Surgery,

Altnagelvin Area Hospital, Londonderry,

Northern Ireland, UK

\section{References}

${ }^{1}$ DiSario JA, Fennerly MB, Tietze CC et al. Endoscopic balloon dilatation for ulcer induced gastric outlet obstruction. Am J Gastroenterol 1994; 89: 868 -871

2 Kozarek RA. Gruntzig balloon dilatation of gastrointestinal stenoses: a national survey. Gastrointest Endosc 1986; 32: $15-19$

${ }^{3}$ Lau JY, Chung SC, Sung JJ et al. Through the scope balloon dilation for pyloric stenosis: long term results. Gastrointest Endosc 1996; 43: 98 - 101

${ }^{4}$ Kozarek RA, Botoman VA, Patterson DJ. Long term follow up in patients who have undergone balloon dilation for gastric outlet obstruction. Gastrointest Endosc 1990; 36: $558-561$

\section{Corresponding Author}

\section{K. J. S. Panesar, M.D., M.B.B.S., L.R.C.P., F.R.C.S}

Department of Surgery Altnagelvin Area Hospital Londonderry BT47 6SB

Northern Ireland, UK

Fax: + 44-2871-611331

E-mail: panesarfrcs@hotmail.com 